NASA/TP-2006-213818

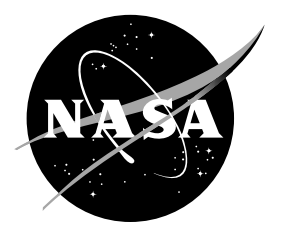

\title{
Precision of Sensitivity in the Design Optimization of Indeterminate Structures
}

Surya N. Patnaik

Ohio Aerospace Institute, Brook Park, Ohio

Shantaram S. Pai and Dale A. Hopkins

Glenn Research Center, Cleveland, Ohio 


\section{NASA STI Program . . . in Profile}

Since its founding, NASA has been dedicated to the advancement of aeronautics and space science. The NASA Scientific and Technical Information (STI) program plays a key part in helping NASA maintain this important role.

The NASA STI Program operates under the auspices of the Agency Chief Information Officer. It collects, organizes, provides for archiving, and disseminates NASA's STI. The NASA STI program provides access to the NASA Aeronautics and Space Database and its public interface, the NASA Technical Reports Server, thus providing one of the largest collections of aeronautical and space science STI in the world. Results are published in both non-NASA channels and by NASA in the NASA STI Report Series, which includes the following report types:

- TECHNICAL PUBLICATION. Reports of completed research or a major significant phase of research that present the results of NASA programs and include extensive data or theoretical analysis. Includes compilations of significant scientific and technical data and information deemed to be of continuing reference value. NASA counterpart of peer-reviewed formal professional papers but has less stringent limitations on manuscript length and extent of graphic presentations.

- TECHNICAL MEMORANDUM. Scientific and technical findings that are preliminary or of specialized interest, e.g., quick release reports, working papers, and bibliographies that contain minimal annotation. Does not contain extensive analysis.

- CONTRACTOR REPORT. Scientific and technical findings by NASA-sponsored contractors and grantees.
- CONFERENCE PUBLICATION. Collected papers from scientific and technical conferences, symposia, seminars, or other meetings sponsored or cosponsored by NASA.

- SPECIAL PUBLICATION. Scientific, technical, or historical information from NASA programs, projects, and missions, often concerned with subjects having substantial public interest.

- TECHNICAL TRANSLATION. Englishlanguage translations of foreign scientific and technical material pertinent to NASA's mission.

Specialized services also include creating custom thesauri, building customized databases, organizing and publishing research results.

For more information about the NASA STI program, see the following:

- Access the NASA STI program home page at http://www.sti.nasa.gov

- E-mail your question via the Internet to help@sti.nasa.gov

- Fax your question to the NASA STI Help Desk at 301-621-0134

- Telephone the NASA STI Help Desk at 301-621-0390

- Write to:

NASA STI Help Desk

NASA Center for AeroSpace Information 7121 Standard Drive Hanover, MD 21076-1320 
NASA/TP—2006-213818

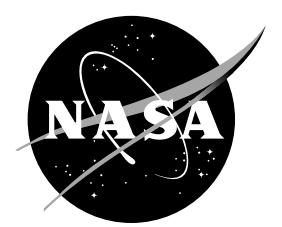

\section{Precision of Sensitivity in the Design Optimization of Indeterminate Structures}

Surya N. Patnaik

Ohio Aerospace Institute, Brook Park, Ohio

Shantaram S. Pai and Dale A. Hopkins

Glenn Research Center, Cleveland, Ohio

National Aeronautics and

Space Administration

Glenn Research Center

Cleveland, Ohio 44135 
This work was sponsored by the Fundamental Aeronautics Program at the NASA Glenn Research Center.

Level of Review: This material has been technically reviewed by a committee of peers.

Available from

NASA Center for Aerospace Information

7121 Standard Drive

Hanover, MD 21076-1320
National Technical Information Service 5285 Port Royal Road Springfield, VA 22161

Available electronically at http://gltrs.grc.nasa.gov 


\title{
Precision of Sensitivity in the Design Optimization of Indeterminate Structures
}

\author{
Surya N. Patnaik \\ Ohio Aerospace Institute \\ Brook Park, Ohio 44142 \\ Shantaram S. Pai and Dale A. Hopkins \\ National Aeronautics and Space Administration \\ Glenn Research Center \\ Cleveland, Ohio 44135
}

\begin{abstract}
Summary
Design sensitivity is central to most optimization methods. The analytical sensitivity expression for an indeterminate structural design optimization problem can be factored into a simple determinate term and a complicated indeterminate component. Sensitivity can be approximated by retaining only the determinate term and setting the indeterminate factor to zero. The optimum solution is reached with the approximate sensitivity. The central processing unit (CPU) time to solution is substantially reduced. The benefit that accrues from using the approximate sensitivity is quantified by solving a set of problems in a controlled environment. Each problem is solved twice: first using the closed-form sensitivity expression, then using the approximation. The problem solutions use the CometBoards testbed as the optimization tool with the integrated force method as the analyzer. The modification that may be required, to use the stiffener method as the analysis tool in optimization, is discussed. The design optimization problem of an indeterminate structure contains many dependent constraints because of the implicit relationship between stresses, as well as the relationship between the stresses and displacements. The design optimization process can become problematic because the implicit relationship reduces the rank of the sensitivity matrix. The proposed approximation restores the full rank and enhances the robustness of the design optimization method.
\end{abstract}

\section{Introduction}

Design sensitivity is central to most optimization methods. It can be a major contributor to the number of calculations in optimization. The computation of efficient design sensitivity for structural problems has drawn considerable attention. NASA organized a conference on the subject matter (ref. 1). It is also well documented in the literature (refs. 2 to 6). General-purpose codes provide for the calculation of sensitivity for stress and displacement constraints (ref. 7). The automatic differentiation of the FORTRAN code, ADIFOR (ref. 8), has also been suggested to calculate sensitivity. In such a circumstance, we ask and attempt to answer a question about the precision of the sensitivity of stress and displacement constraints in the design optimization of an indeterminate structure: "Is the optimization process robust when the design sensitivity matrix is highly accurate?" The contrary may be true. The performance of an optimization method can be improved when the analytical sensitivity is replaced by a determinate approximation. The approximate sensitivity matrix is not only adequate, but it should be preferred in the design calculation of an indeterminate structure. Optimization, in other words, requires sensitivity, but approximate gradients are quite satisfactory. To illustrate the benefits that accrue from the approximations, the authors used several indeterminate trusses as numerical examples because design optimizations have been completed for such structures. The concept, however, should be extendable to other types of structures, such as beams, framework, and shell structures.

Consider a truss that is made of $n$ bars with $r$ dependent members. The $n$ bar areas are treated as the design variables. Approximate sensitivity works well because of three attributes special to an indeterminate truss. 
(1) Dependent stresses: In an indeterminate truss, $r$ out of $n$ bar stresses $\{\sigma\}$ are dependent. Stresses are dependent because of the $r$ compatibility conditions, which can be written as $[\bar{C}]\{\sigma\}=\{0\}$. The $r \times n$ sparse matrix $[\bar{C}]$ is independent of the design variables.

(2) Dependency of stresses and displacements: The $m=n-r$ number of displacements $\{X\}$ are dependent on the $n$ bar stresses: $\{X\}=[\bar{B}]^{T}\{\sigma\}$. The $m \times n$ sparse matrix $[\bar{B}]$ is independent of the design variables.

(3) Active constraints: In structural design, the number of active constraints can exceed the number of design variables. In an optimization algorithm, the singularity condition can be alleviated by restricting the number of active constraints to not exceed the number of design variables.

In an optimization algorithm, the calculation of the search direction $\{d\}$ requires the constraint gradient matrix $[\nabla g]$. An example of the use of the sensitivity matrix to generate the direction follows:

$$
\begin{gathered}
\{d\}=[Q]\{\nabla f\} \\
{[Q]=-\frac{[I]-[\nabla g]\left[[\nabla g]^{T}[\nabla g]\right]^{-1}[\nabla g]^{T}}{0.5 \sqrt{\{[H]\{\nabla f\}\}^{T}\{[H]\{\nabla f\}\}}}}
\end{gathered}
$$

Here $f$ is the objective function, and

$$
[H]=[I]-[\nabla g]\left[[\nabla g]^{T}[\nabla g]\right]^{-1}[\nabla g]^{T}
$$

The matrix $\left[[\nabla g]^{T}[\nabla g]\right]$ becomes singular for each of the three special attributes, items (1) to (3), stated above. An optimization algorithm may yield a solution despite the singularity condition because the $[Q]$ matrix is approximated most often; it is seldom calculated in closed form. It is reinitialized into an identity matrix when corruption is suspected. The proposed approximate sensitivity of stress and displacement constraints alleviates the singularity condition in the design optimization of an indeterminate truss. The solution is reached with fewer calculations because the optimization process becomes more robust, and the sensitivity is generated with a trivial amount of computations. The benefit that accrues from the use of approximate sensitivity is shown through the solution of a set of problems that were selected from the literature. Each problem was solved twice in a controlled environment, first using the closed-form gradient, then with an approximation. A comparison of the two optimum solutions quantified the benefit. The underlying cause of the benefit was investigated through a discussion of the nature of structural design optimization problems.

This paper is organized into six subsequent sections. The design problem is formulated in the second section. The analysis and optimization tools are discussed in the third and fourth sections, respectively. Solutions to a set of problems are given in the fifth section, followed by a discussion and conclusions in the sixth section. A symbols list is given in the appendix to aid the reader.

\section{Design Optimization Problem}

Minimum weight is the objective of the truss design problem. The bar areas $A_{i}$ are considered as the design variables. Limitations specified on the bar stress $\sigma_{i}$ and nodal displacement $u_{j}$ form the behavior constraints. The design optimization is cast as the following mathematical programming problem. 
Find $n$ design variables, here bar areas $\{A\}$ :

To minimize the weight of the truss,

$$
W(A)=\sum_{i=1}^{n} \rho_{i} A_{i} \ell_{i}
$$

under $n$ stress constraints,

$$
g_{i}(A)=\left|\frac{\sigma_{i}}{\sigma_{i 0}}\right|-1 \leq 0
$$

and $m$ displacement constraints,

$$
g_{n+j}(A)=\left|\frac{u_{j}}{u_{j 0}}\right|-1 \leq 0
$$

Here $\rho_{i}$ and $\ell_{i}$ are the weight density and length, $\sigma_{i}$ and $\sigma_{i 0}$ are the stress and allowable strength, and $u_{j}$ and $u_{j 0}$ are the nodal displacement and limitation, respectively. For a large problem, the number of design variables can be reduced by linking bar areas. Likewise, a small number of critical constraints can be separated and used in the design calculations (ref. 9).

\section{Design Update Formula}

A key formula to update the design variables (here area $A_{i}$ ) in a nonlinear programming algorithm at a $k^{\text {th }}$ intermediate iteration can be written as

$$
\{A\}_{k}=\{A\}_{k-1}+\alpha_{k-1}\{d\}_{k-1}
$$

The step length $\alpha_{k-1}$ is calculated to minimize the weight along the direction $\{d\}_{k-1}$ inside the feasible domain. All $n+m$ constraints should be used to define the feasible space. The sensitivities of the set of active stress and displacement constraints are required to calculate the direction vector $\{d\}_{i-1}$. The quality of the direction vector is dependent on the accuracy of the sensitivity matrix. A spurious direction would be generated if the sensitivity matrix was rank deficient.

Consider the $j^{\text {th }}$ stress constraint. Its closed-form gradient can be expressed as the sum of two factors:

$$
\left\{\nabla g_{j}\right\}=\frac{1}{\sigma_{j 0}}\left\{\left\{\nabla \sigma_{j}\right\}^{\text {determinate }}+\left\{\nabla \sigma_{j}\right\}^{\text {indeterminate }}\right\}
$$

The gradient expression given by equation (4) has to be adjusted for the absolute value in the constraint, which however, poses no limitation to the discussion here. The first factor $\left\{\nabla \sigma_{j}\right\}^{\text {determinate }}$ is applicable to determinate as well as indeterminate trusses. This vector has only one nonzero entry, which is the negative ratio of the member force to the square of the bar area $\left(-F / A^{2}\right)$. The second term $\left\{\nabla \sigma_{j}\right\}^{\text {indeterminate }}$ accounts for the effect of indeterminacy. It is not a negligible factor. It can be fully populated, and its calculation is computationally intensive. The proposition is to drop the second term $\left\{\nabla \sigma_{j}\right\}^{\text {indeterminate }}$ in design optimization even when it is nontrivial. The nature of the gradient of the displacement constraint is quite similar to that of the stress constraint. Again, the proposition is to retain only the simple determinate factor.

\section{Analysis Tool}

An analysis tool is required to calculate the stress and displacement constraints and their sensitivities. Here, the integrated force method (IFM) (ref. 10) is employed. The structure of the IFM equation is suitable to calculate the closed-form sensitivities because the sizing design variables of a structure (here bar areas) are retained in a pristine state in the concatenated flexibility matrix [G]. In addition, IFM has 
two distinct sets of equations. The first set, with internal force as the primary unknown, is differentiated to obtain the sensitivity of stress. Likewise, the sensitivity of displacement is recovered by differentiating the second set of equations. The adjustment that may be required for the stiffness method of analysis is also discussed in this paper. The IFM equations to calculate forces and back-calculate displacements are as follows:

Internal forces $\{F\}$ are calculated from the governing IFM equation:

$$
[S]\{F\}=\{P\}
$$

Displacements $\{X\}$ are back-calculated from the forces:

$$
\{X\}=[J][G]\{F\}
$$

Here

$$
[S]=\left[\begin{array}{c}
{[B]} \\
---- \\
{[C][G]}
\end{array}\right]
$$

and

$[S] \quad n \times n$ governing matrix

[B] $\quad m \times n$ equilibrium matrix

[C] $\quad r \times n$ compatibility matrix

$[G] \quad n \times n$ flexibility matrix

$\{F\} \quad n$-component force vector

$\{P\} \quad n$-component load vector, $\{P\}=\left\{\begin{array}{c}P^{m} \\ --- \\ \delta R\end{array}\right\}$

$\left\{P^{m}\right\} \quad m$-component mechanical load vector

$\{\delta R\} \quad r$-component initial load vector, $r=n-m$

$\{X\} \quad m$-component displacement vector

[J] first $m$ rows of $\left[[S]^{-1}\right]^{T}$ matrix of dimension $m \times n$

The sensitivity matrix for the stress and displacement constraints for an $n$-bar truss with $r$ dependent members is obtained by differentiating the IFM equations. The closed-form sensitivity matrix for stress has the following form (ref. 11):

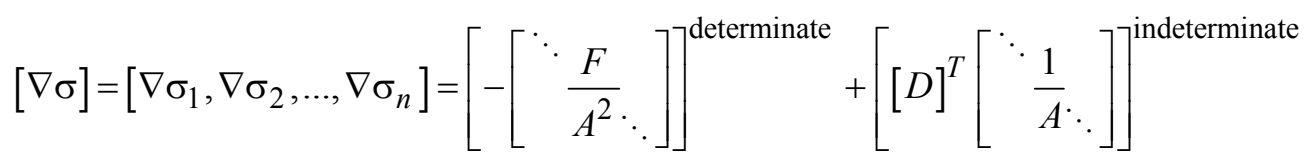

The expression given by equation (7) should be adjusted for the allowable strength prior to its use in design optimization. The rank of the $n \times n$ sensitivity matrix $[\nabla \sigma]$ in equation (7) is reduced to $m=n-r$ when both terms are retained. The recommendation is to use only the first term in equation (7), which is superscripted "determinate." It is a diagonal matrix with full rank $n$. The proposition is to drop the second term that is superscripted "indeterminate." The calculation of this term is computation intensive. 
The closed-form displacement sensitivity follows:

$$
[\nabla X]=\left[\left[[J]\left[\because S_{d g} \cdot .\right]\right]^{\text {determinate }}+[[J][G][D]]^{\text {indeterminate }}\right]^{T}
$$

The proposition is to use the first factor with superscript "determinate" in design optimization. The definitions of the symbols in equations (7) and (8) are as follows:

$$
[D]=[S]^{-1}\left[\begin{array}{c}
{[0]} \\
---- \\
{[C]\left[\begin{array}{c}
= \\
G
\end{array}\right]}
\end{array}\right][\bar{F}]
$$

The elements of the diagonal matrix $\left[{ }^{\prime} S_{d g} \cdot\right.$. $]$ are given by

$$
\left(S_{d g}\right)_{i i}=-\frac{g_{i i} F_{i}}{A_{i}}=-\frac{\ell_{i} F_{i}}{A_{i}^{2} E_{i}}
$$

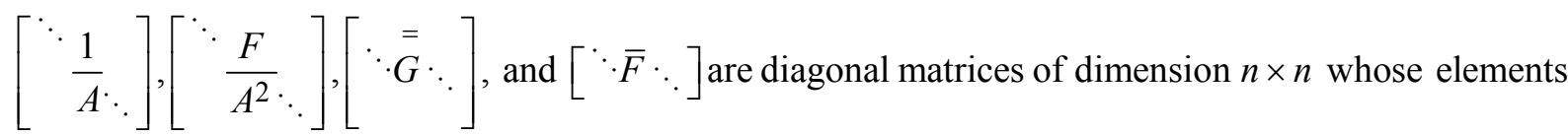
are $\frac{1}{A_{i}}, \frac{F_{i}}{A_{i}^{2}}, \frac{\ell_{i}}{A_{i}^{2} E_{i}}$, and $F_{i}$, respectively.

The determinate factor in the displacement sensitivity can be specialized for an $n$-bar indeterminate truss as

$$
[\nabla X]^{\text {determinate }}=\left[[J]\left[S_{d g}\right]\right]^{T}=\left(\begin{array}{lll}
\ddots & & 0 \\
& \frac{-F \ell}{A^{2} E} & \\
0 & & \ddots
\end{array}\right)[J]^{T}
$$

The displacement sensitivity given by equation (9) is a function of the bar length $\ell$, Young's modulus $E$, and areas $A$ because displacement is a global variable. Calculation of the determinate sensitivity for the displacement essentially requires a back-substitution step with the factored form of the inverse of the $S$ matrix. It is important to observe the similarities and differences in the sensitivity expressions of the stress and displacement.

(1) Sensitivities of both the stress and displacement contain the member forces $\{F\}$ and the square of bar areas $\{A\}$. Even for an active displacement constraint, the design in essence is modified through the member force.

(2) The geometry of the truss is not explicitly contained in the sensitivity expression for stress because it is a local variable.

(3) Because displacement is a global variable, its sensitivity expression explicitly contains the geometrical or configuration parameters, the material property, and the design variables. 


\section{Optimization Tool}

The consequences of using approximate sensitivity in design optimization are demonstrated through the solution of a set of problems. Solutions were generated within the framework of the design optimization testbed CometBoards (ref. 12). Each problem was solved twice, first using the determinate sensitivity, then with the full closed-form expression. Problems were solved in a controlled environment on an SGI workstation running the IRIX 6.5 operating system (Silicon Graphics, Inc., Mountain View, CA). Identical convergence and stop criteria were used for the optimization algorithm. For large problems, we reduced the number of design variables and constraints by utilizing the design variable linking and constraint formulation features available in CometBoards. A sequential quadratic programming algorithm, SQP (ref. 12), was the primary optimizer. This algorithm was supplemented, when required, by a modified method of feasible directions (mFD) and a sequential unconstrained minimization technique (SUMT).

Research to compare different optimization algorithms and alternate analysis methods for structural design applications has grown into a multidisciplinary design testbed that is still referred to by its original acronym, CometBoards, which stands for COMparative Evaluation Test Bed of Optimization and Analysis Routines for the Design of Structures. The modular organization of CometBoards, shown in figure 1, allows for quick testing of innovative methods (or computer codes) in a controlled environment through its soft-coupling feature. Optimizers and analyzers are two important modules of CometBoards.

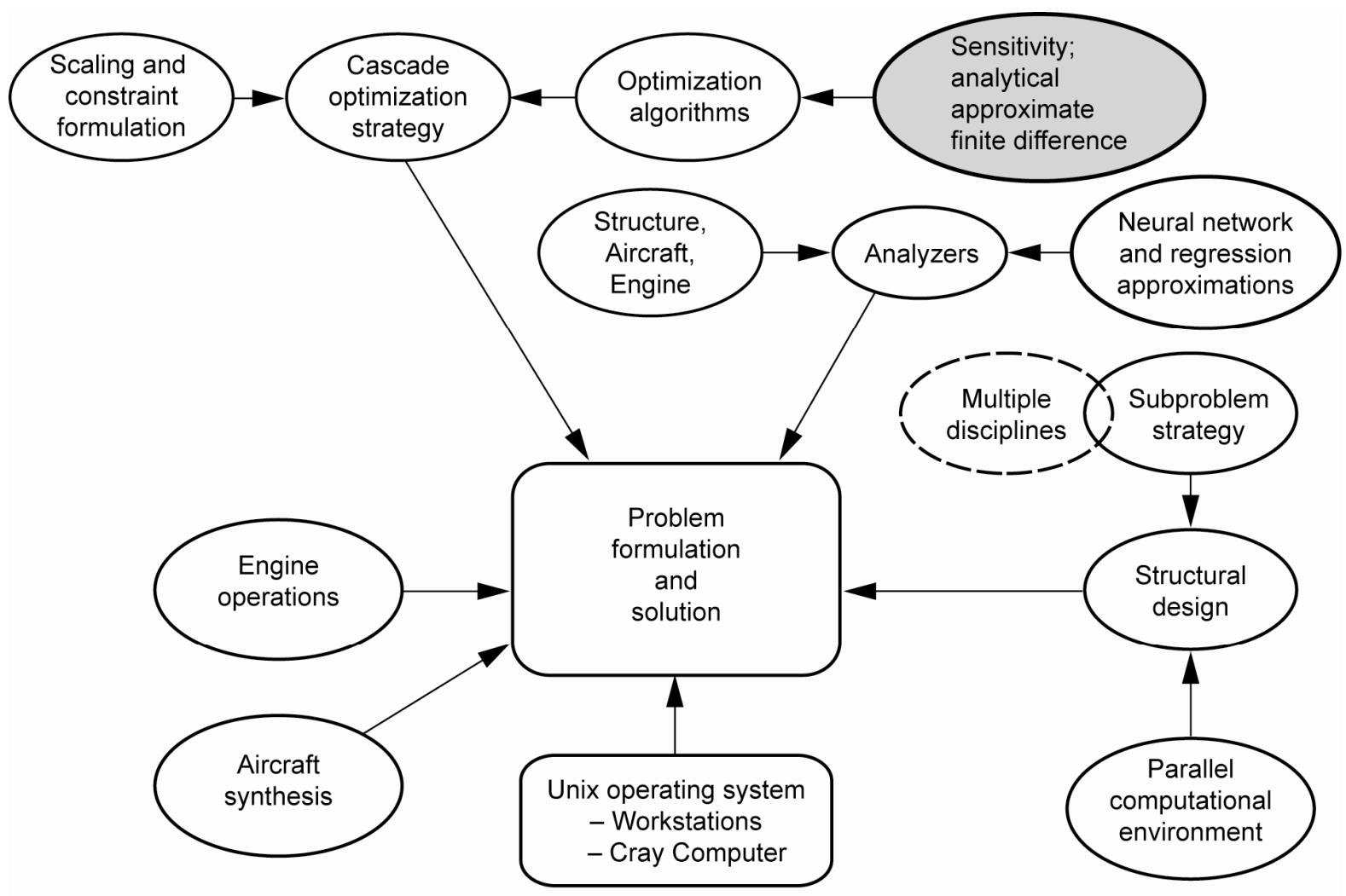

Figure 1.-Organization of the design optimization testbed COMETBOARDS. 
The optimizer module includes a number of algorithms: the fully utilized design method, optimality criteria methods, the method of feasible directions, $\mathrm{mFD}$, three different versions of SQP techniques, SUMT, the sequence of linear programming, a reduced gradient method, and others. Likewise, the analyzer module includes several structural analysis codes, an aircraft flight optimization analyzer, a jet engine performance program, and others. CometBoards has several unique features, including a multiple optimizer cascade strategy, design variable and constraint formulations, a global scaling strategy, analysis and sensitivity approximations, regression and neural network approximators, and substructure optimization in sequential as well as in parallel computational platforms. CometBoards can accommodate up to 10 different disciplines, each of which can have a maximum of five subproblems. The testbed can optimize a large system that can be defined in as many as 50 different subproblems. Alternatively, a component of a large system can be optimized.

\section{Numerical Examples}

Solutions were generated for a set of six examples. The number of design variables ranged between 3 and 23 linked variables. The constraints ranged between 7 and 312. First, we summarize each problem and provide its optimum solution. This is followed by the CPU time to solution. We conclude the section with a discussion on the search direction.

\section{Numerical Example 1: A Three-Bar Truss}

The optimum solution was calculated for the three-bar steel truss shown in figure 2 using the determinate term as well as the full-sensitivity expression. The truss in this figure was subjected to three different load cases. A 100-kip load along the negative $y$-coordinate direction at the free node 1 was the first load case. The second and third load cases consisted of a 100-kip load in the positive and negative $x$-coordinate directions, respectively. The three bar areas were the design variables, and minimum weight was the objective. The allowable stress was $20 \mathrm{ksi}$ for each member. The displacement limitations were 0.25 and $0.50 \mathrm{in}$. at node 1 along the $x$ and $y$ directions, respectively. There were a total of nine stress and six displacement constraints. The problem was solved using the SQP algorithm, and the optimum solution is given in table $\mathrm{I}$.

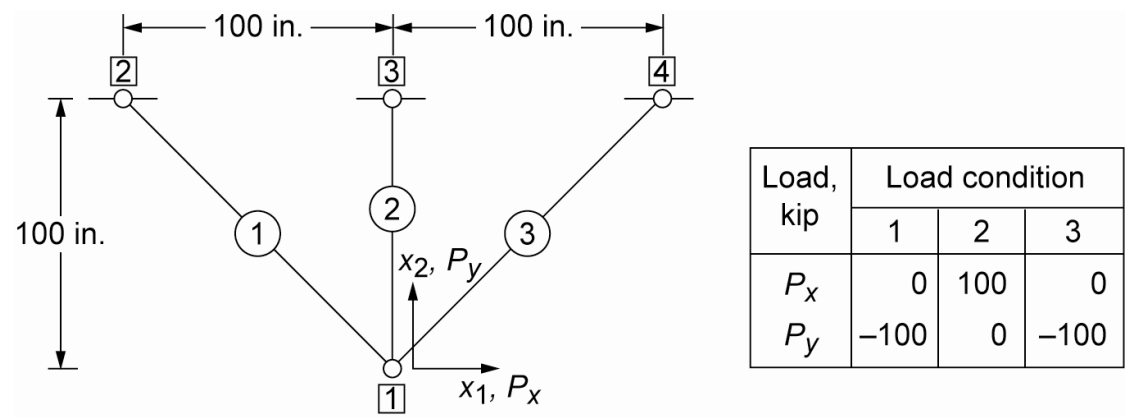

Figure 2.-Three-bar truss. 
TABLE I.-OPTIMUM SOLUTION FOR THE THREE-BAR TRUSS

\begin{tabular}{|c|c|c|c|c|c|c|}
\hline \multirow{2}{*}{$\begin{array}{c}\text { Weight, } \\
\text { lbf }\end{array}$} & \multicolumn{3}{|c|}{$\begin{array}{c}\text { Design variables, } \\
\text { in. }{ }^{2}\end{array}$} & \multicolumn{2}{c|}{ Active constraints } & \multirow{2}{*}{ Sensitivity } \\
\cline { 2 - 6 } & $A_{1}$ & $A_{2}$ & $A_{3}$ & Stress & Displacement & \\
\hline 163.6 & 1.89 & 0.33 & 1.89 & 1 & 2 & Determinate \\
163.8 & 1.89 & 0.33 & 1.89 & 1 & 2 & Analytical \\
\hline
\end{tabular}

The SQP algorithm converged to the same optimum solution for the determinate as well as for the full-sensitivity expression. At the optimum, the rank of the sensitivity matrix was 2 and 3 for the analytical and determinate sensitivity expressions, respectively. The three-variable problem had three active constraints.

\section{Numerical Example 2: A Tapered Five-Bar Truss}

The optimum solution was obtained for the tapered five-bar steel truss shown in figure 3 . The truss geometry and loads are depicted in the figure. The allowable stress was $20 \mathrm{ksi}$, and the displacement limitations were 0.25 and $0.50 \mathrm{in}$. at node 2 along the $x$ and $y$ directions, respectively. The five-bar areas were the design variables, with a 0.25 -in. ${ }^{2}$ lower bound on bar areas. The problem had a total of seven constraints. It was solved using three algorithms: SQP, $\mathrm{mFD}$, and SUMT. The optimum solutions are given in table II.

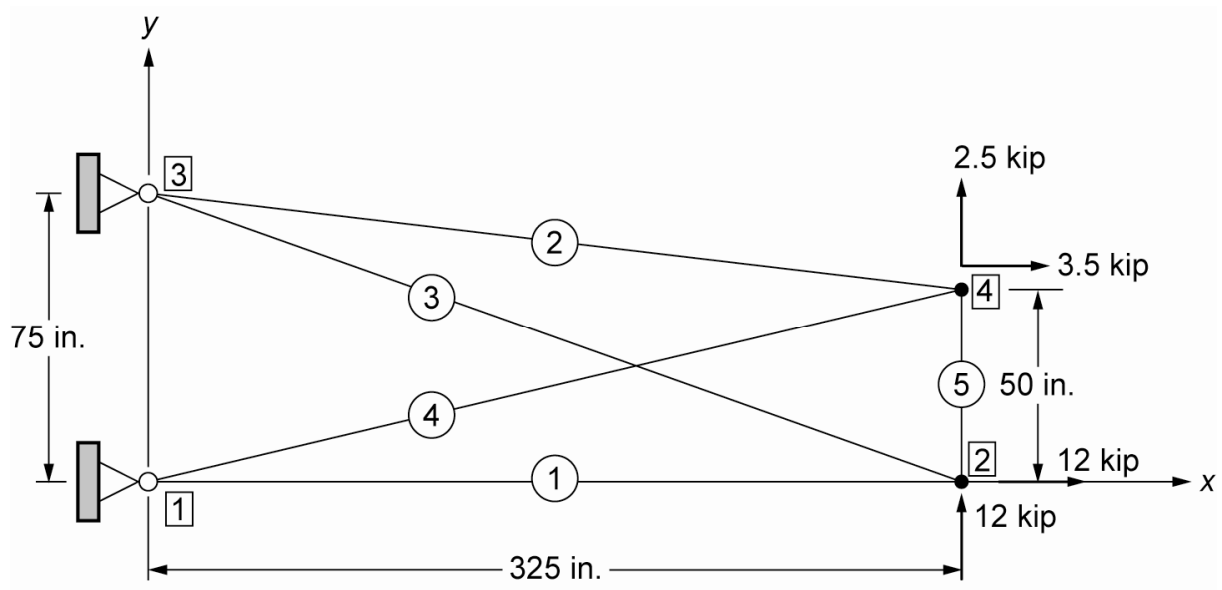

Figure 3.-Tapered five-bar truss. 
TABLE II.-OPTIMUM SOLUTIONS FOR THE FIVE-BAR TRUSS

\begin{tabular}{|c|c|c|c|c|c|c|c|c|c|}
\hline \multirow[t]{2}{*}{ Method } & \multirow[t]{2}{*}{$\begin{array}{c}\text { Weight, } \\
\text { lbf }\end{array}$} & \multicolumn{5}{|c|}{$\begin{array}{c}\text { Design variables, } \\
\text { in. }^{2}\end{array}$} & \multicolumn{2}{|c|}{ Active constraints } & \multirow[t]{2}{*}{ Sensitivity } \\
\hline & & $A_{1}$ & $A_{2}$ & $A_{3}$ & $A_{4}$ & $A_{5}$ & Stress & Displacement & \\
\hline SQP & 645.0 & 2.21 & 1.41 & 1.65 & 1.60 & 0.25 & 5 & 2 & Determinate \\
\hline $\mathrm{mFD}$ & 646.7 & 0.84 & 2.78 & 0.25 & 2.98 & 0.63 & 4 & 2 & Determinate \\
\hline SUMT & 646.8 & 1.74 & 1.89 & 1.17 & 2.09 & 0.34 & 5 & 2 & Determinate \\
\hline SQP & 646.2 & 2.48 & 1.15 & 1.93 & 1.34 & 0.25 & 4 & 2 & Analytical \\
\hline $\mathrm{mFD}$ & 648.5 & 1.81 & 1.83 & 1.24 & 2.03 & 0.37 & 4 & 2 & Analytical \\
\hline SUMT & 647.7 & 1.81 & 1.82 & 1.25 & 2.01 & 0.36 & 4 & 2 & Analytical \\
\hline
\end{tabular}

This example appears to have multiple optimum solutions with about the same weight of $646 \mathrm{lbf}$. The SQP, $\mathrm{mFD}$, and SUMT algorithms converged to different optimum solutions with a small variation in the weight. For determinate sensitivity, the mean weight was $646.2 \mathrm{lbf}$, with a maximum deviation of about 0.2 percent. For the closed-form sensitivity, the weight was marginally higher at $647.5 \mathrm{lbf}$, also with a 0.2 -percent variation. The variation in area was rather wide. Consider, for example, the area for the first bar. For the full-sensitivity expression, its mean was $2.0 \mathrm{in.}^{2}$, with a maximum deviation of 22 percent. For the approximation, the mean was 1.6 in. ${ }^{2}$, with a maximum variation of 47 percent. The sum of the areas for bar 1 and bar 2 remained at 3.62 in. $^{2}$ When bar 1 became heavier, bar 2 became lighter and vice versa. The active constraint set included two displacement limitations and either four or five stress constraints. The determinate sensitivity performed at about the same level as the closed-form gradients. The five-variable problem with six active constraints was not a well-posed mathematical programming problem (ref. 9).

\section{Numerical Example 3: A Forward-Swept Wing}

A forward-swept wing made of aluminum was modeled as a space truss with 135 bars, as shown in figure 4. It was subjected to loads at the wing tip that induced flexure in the $x-z$ plane and torsion in the $y$-z plane. The allowable stress was $\sigma_{0}=10 \mathrm{ksi}$ for all members. Displacements along the $z$-coordinate direction were constrained at nodes 10 and 30 with a 2-in. limitation. The 135 bar areas were grouped to obtain 23 linked design variables. The problem had 135 stress and two displacement constraints. The optimum solutions obtained by the SQP and SUMT algorithms are given in table III. The SQP algorithm converged to the minimum weights of 4218.5 and $4217.9 \mathrm{lbf}$ for analytical and determinate sensitivities, respectively. For the SUMT algorithm, the weights were 4072.7 and $4071.5 \mathrm{lbf}$, respectively. The 3.5-percent difference in the minimum weight between the algorithms could be attributed to the complexity of the problem. The mean values of the design variables are depicted in table III. Eight variables converged to the lower bound $\left(0.25\right.$ in. $\left.^{2}\right)$. There were six and nine variables, above and below the mean value, respectively. A consistent set of active constraints was generated for the determinate as well as the analytical sensitivities. However, there were more active constraints than the number of design variables. The mFD algorithm converged to a heavy design that was considered incorrect and excluded from discussion. The solution with approximate sensitivity required a much smaller number of calculations. The central processing unit (CPU) time to solution for the determinate and the closed-form sensitivities was reduced by factors of 7.8 and 5.5 for the SQP and SUMT methods, respectively. 


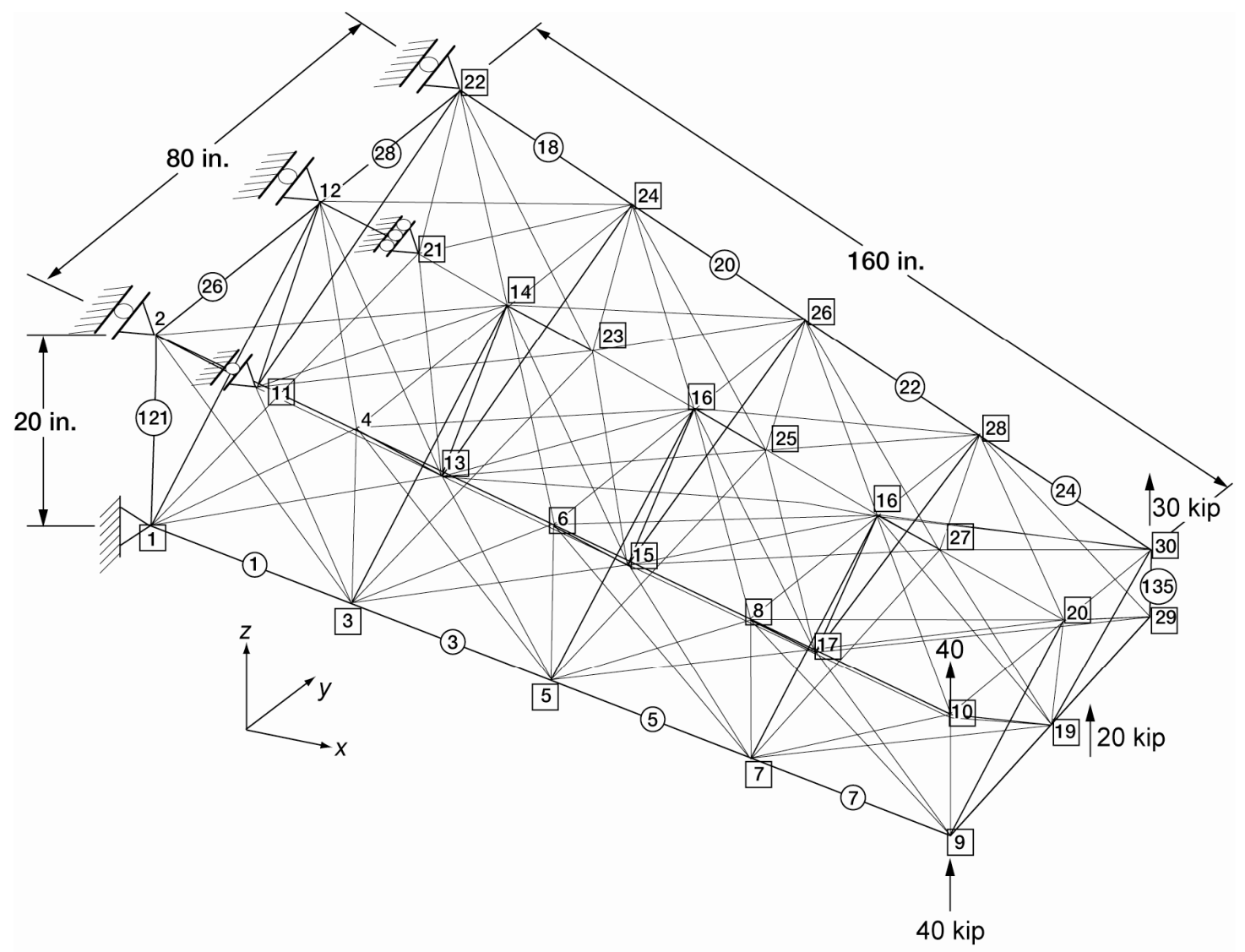

Figure 4.-Forward-swept wing.

TABLE III.-OPTIMUM SOLUTIONS FOR THE FORWARD-SWEPT WING

\begin{tabular}{|c|c|c|c|c|c|c|}
\hline \multirow[t]{2}{*}{ Method } & \multirow{2}{*}{$\begin{array}{c}\text { Weight, } \\
\text { lbf }\end{array}$} & \multirow{2}{*}{$\begin{array}{l}\text { Mean value of } \\
\text { design } \\
\text { variables, } \\
\text { in. }{ }^{2}\end{array}$} & \multicolumn{2}{|c|}{ Active constraints } & \multirow{2}{*}{$\begin{array}{l}\text { CPU } \\
\text { time, } \\
\text { sec }\end{array}$} & \multirow[t]{2}{*}{ Sensitivity } \\
\hline & & & Stress & Displacement & & \\
\hline SQP & 4217.9 & 7.34 & 20 & 1 & 8.7 & Determinate \\
\hline SUMT & 4071.5 & 7.11 & 24 & 1 & 6.2 & Determinate \\
\hline SQP & 4218.5 & 7.35 & 20 & 1 & 67.5 & Analytical \\
\hline SUMT & 4072.7 & 7.11 & 24 & 1 & 34.0 & Analytical \\
\hline
\end{tabular}

\section{Numerical Example 4: A Trussed Ring}

The design of the trussed steel ring shown in figure 5 was considered next. The ring was made of 60 bars and had inner and outer diameters of 180 and 200 in., respectively. It was fully restrained at node 10 and free to move only along the $y$ direction at the diametrically opposite node 16 . The ring was subjected to two load conditions. The first load condition consisted of a 40-kip compression along the ring's horizontal diameter, which was applied at nodes 1 and 7. In the second case, a 40-kip load was applied at node 4 to induce compression along the vertical diameter. 


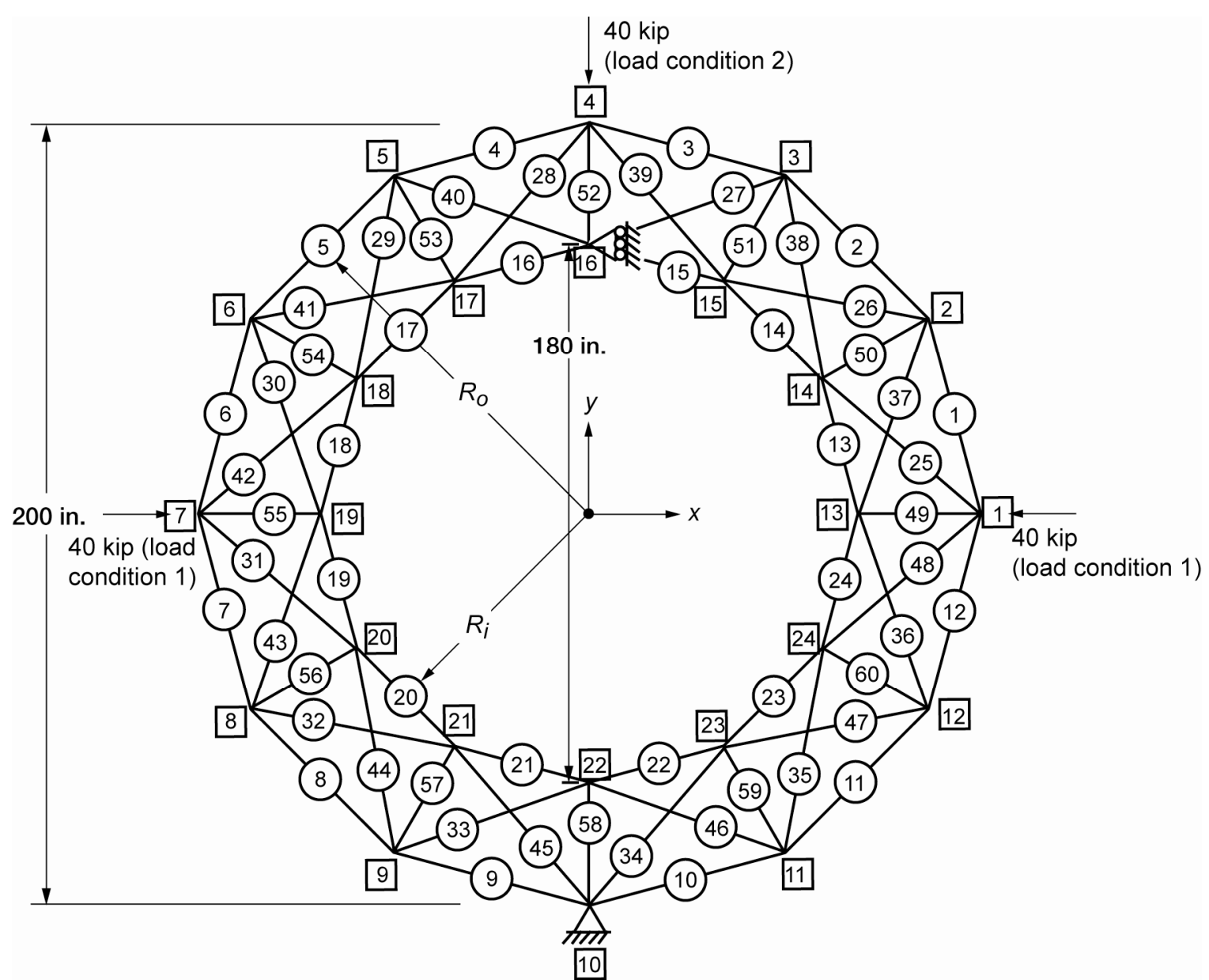

Figure 5.-Sixty-bar trussed ring.

The 60 bar areas of the truss were grouped to obtain 16 linked design variables. The ring had 60 stress constraints (with a yield strength of $20 \mathrm{ksi}$ ) for each load condition. The distortions of the ring along the horizontal and vertical diameters were controlled through a 4-in. displacement limitation specified at nodes 1,4 , and 7 for each load condition. The problem had a total of 120 stress and 6 displacement constraints. Optimum solutions generated by SQP and SUMT algorithms are given in table IV. Mean, maximum, and minimum values are given for the 16 design variables.

TABLE IV.-OPTIMUM SOLUTION FOR THE TRUSSED RING

\begin{tabular}{|c|c|c|c|c|c|c|c|c|}
\hline \multirow[t]{3}{*}{ Method } & \multirow[t]{3}{*}{$\begin{array}{c}\text { Weight, } \\
\text { lbf }\end{array}$} & \multicolumn{3}{|c|}{$\begin{array}{l}\text { Design variables, } \\
\text { in. }^{2}\end{array}$} & \multicolumn{2}{|c|}{ Active constraints } & \multirow{3}{*}{$\begin{array}{c}\mathrm{CPU} \\
\text { time, } \\
\mathrm{sec}\end{array}$} & \multirow[t]{3}{*}{ Sensitivity } \\
\hline & & \multirow{2}{*}{$\begin{array}{l}\text { Mean } \\
\text { value }\end{array}$} & \multicolumn{2}{|c|}{ Variation } & \multirow[t]{2}{*}{ Stress } & \multirow{2}{*}{ Displacement } & & \\
\hline & & & Minimum & Maximum & & & & \\
\hline SQP & 799.9 & 3.15 & 2.18 & 4.05 & 28 & 1 & 2.3 & Determinate \\
\hline SUMT & 797.7 & 3.15 & 2.18 & 4.01 & 28 & 1 & 1.3 & Determinate \\
\hline SQP & 799.9 & 3.15 & 2.18 & 4.04 & 28 & 1 & 7.4 & Analytical \\
\hline SUMT & 798.0 & 3.15 & 2.19 & 4.00 & 28 & 1 & 7.1 & Analytical \\
\hline
\end{tabular}

Both SQP and SUMT algorithms with approximate as well as full closed-form sensitivities converged to the same solution with a 0.25 -percent deviation in the minimum weight. The CPU time to solution was 321 and 318 percent faster for approximate sensitivity with the SQP and SUMT algorithms, respectively. The 16-variable problem had 29 active constraints. 


\section{Numerical Example 5: A 25-Bar Truss}

The aluminum tower modeled as the 25-bar space truss shown in figure 6 was designed for minimum weight under stress and displacement constraints. It was subjected to two load conditions. In the first load case, node 1 was subjected to three load components: 5-, 20-, and -5-kip forces along the $x, y$, and $z$ axes, respectively. In the second load case, node 2 was subjected to -20- and -5-kip forces along the $y$ and $z$ axes, respectively.

The allowable stress was $10 \mathrm{ksi}$, and the displacement limitation was $1 \mathrm{in}$. in all three directions for the six free nodes. The 25 bar areas were linked to obtain eight design variables. The problem had 25 stress and 18 displacement constraints. The optimum solutions calculated by the SQP and mFD algorithms are given in table $\mathrm{V}$. The mean value and variance are given for the eight design variables. The eight-variable problem had nine active constraints. Both the SQP and $\mathrm{mFD}$ algorithms converged to the same optimum solution for the determinate as well as the analytical gradients.

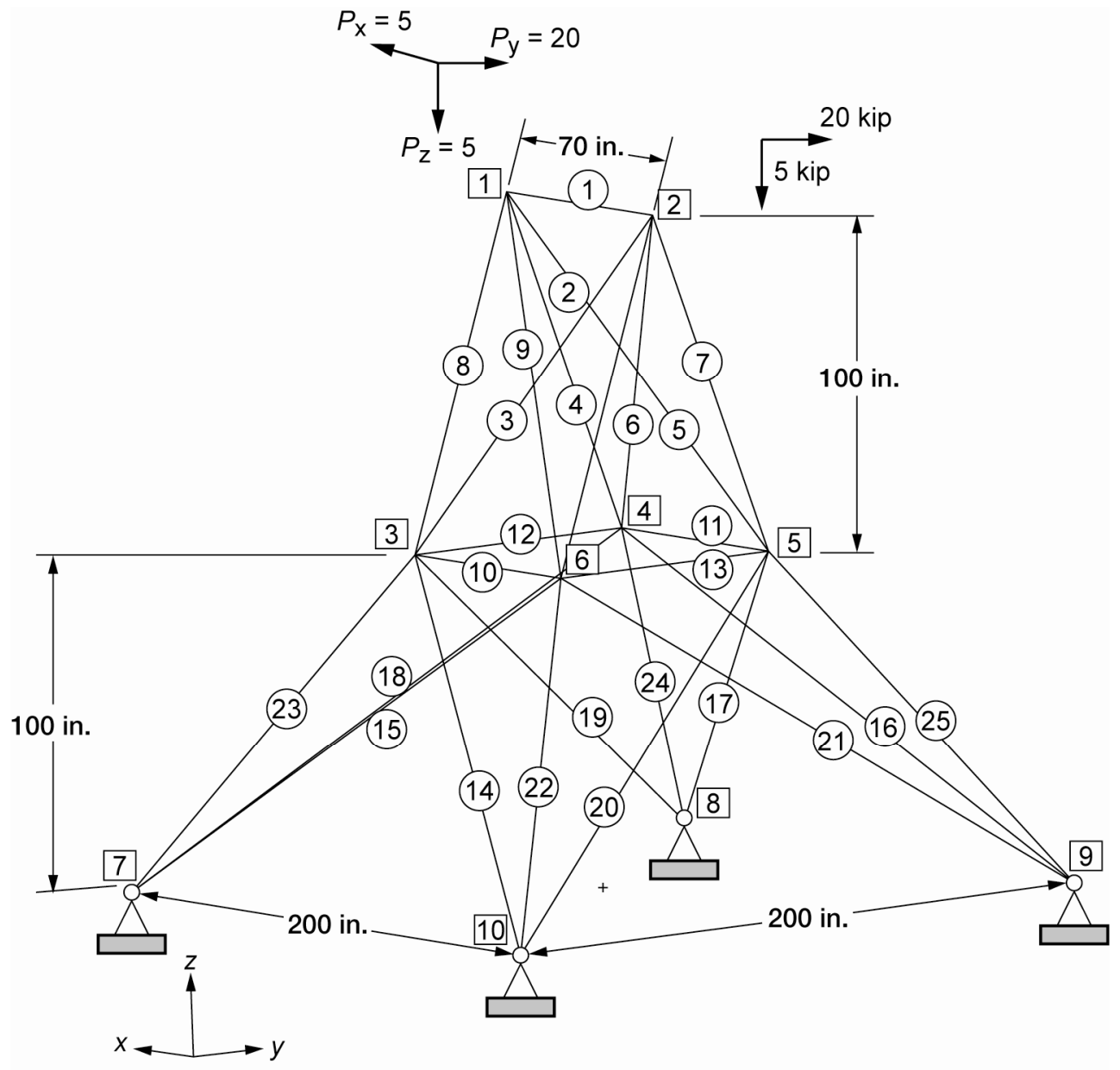

Figure 6.-Twenty-five bar tower. 
TABLE V.-OPTIMUM SOLUTIONS FOR THE 25-BAR TRUSS

\begin{tabular}{|l|c|c|c|c|c|c|}
\hline \multirow{2}{*}{ Method } & \multirow{2}{*}{$\begin{array}{c}\text { Weight, } \\
\text { lbf }\end{array}$} & \multicolumn{2}{|c|}{$\begin{array}{c}\text { Design variables, } \\
\text { in. }^{2}\end{array}$} & \multicolumn{2}{c|}{ Active constraints } & \multirow{2}{*}{ Sensitivity } \\
\cline { 3 - 6 } & & Mean value & Variance & Stress & Displacement & \\
\hline SQP & 190.5 & 0.49 & 0.13 & 7 & 2 & Determinate \\
mFD & 190.6 & 0.49 & 0.13 & 7 & 2 & Determinate \\
\hline SQP & 190.5 & 0.49 & 0.13 & 7 & 2 & Analytical \\
mFD & 190.4 & 0.49 & 0.13 & 7 & 2 & Analytical \\
\hline
\end{tabular}

\section{Numerical Example 6: A 20-Bay Truss}

The minimum-weight design was calculated for the 20-bay steel truss shown in figure 7 . The structure in the figure was subjected to three load cases. The first load case consisted of forces in the negative $y$-coordinate direction along the bottom chord nodes: -40 kip at the midspan and -1 kip at the other nodes. For the second load case, all the top chord nodes were subjected to a 3-kip force along the $x$-coordinate direction. For the third load case, all the bottom chord nodes were subjected to a-3-kip force along the negative $x$-coordinate direction.

The allowable stress was $\sigma_{0}=20 \mathrm{ksi}$. A displacement limitation of $0.5 \mathrm{in}$. was imposed at the midspan nodes 21 and 22 along the $x$ - and $y$-coordinate directions, respectively. The 101 bar areas were grouped to obtain five linked design variables. The first two design variables represented the bar area of the top and bottom chord members, respectively. All 21 vertical bar areas were grouped to obtain the third variable. The last two design variables represented the bar area of the leading and lagging diagonal members, respectively. The five-variable problem had a total of 312 stress and displacement constraints. Optimum solutions obtained by the SQP algorithm are given in table VI.

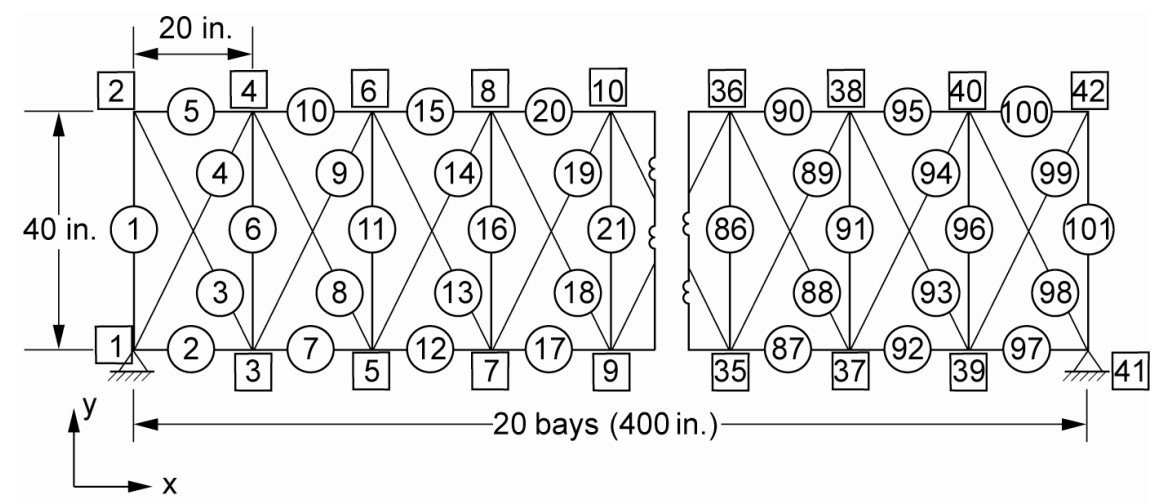

Figure 7.-Twenty-bay truss. 
TABLE VI.-OPTIMUM SOLUTIONS FOR THE 20-BAY TRUSS

\begin{tabular}{|c|c|c|c|c|c|c|c|c|c|}
\hline \multirow[t]{2}{*}{$\begin{array}{c}\text { Weight, } \\
\text { lbf }\end{array}$} & \multicolumn{5}{|c|}{$\begin{array}{c}\text { Design variables, } \\
\text { in. }^{2}\end{array}$} & \multicolumn{2}{|c|}{ Active constraints } & \multirow{2}{*}{$\begin{array}{l}\text { CPU } \\
\text { time, } \\
\text { sec }\end{array}$} & \multirow[t]{2}{*}{ Sensitivity } \\
\hline & $A_{1}$ & $A_{2}$ & $A_{3}$ & $A_{4}$ & $A_{5}$ & Stress & Displacement & & \\
\hline 2023.2 & 3.44 & 7.03 & 0.41 & 1.38 & 1.38 & 3 & 1 & 2.5 & Determinate \\
\hline 2021.8 & 3.44 & 6.99 & 0.41 & 1.39 & 1.39 & 3 & 1 & 14.8 & Analytical \\
\hline
\end{tabular}

The SQP algorithm converged to the same solution for the determinate as well as for the analytical sensitivities. With the approximation, the CPU time to solution was 590 percent faster. With five design variables and four active constraints, this was a well-posed mathematical programming problem.

\section{Computational Efficiency}

All six examples converged to the correct solution with the approximate sensitivity. To examine the computational efficiency when the approximate sensitivity was used, we solved the three larger problems: the ring, the wing, and the 20-bay truss in a controlled environment using the SQP algorithm on an SGI workstation with an IRIX 6.5 operating system. The CPU time to optimum solution was measured for both the determinate and the closed-form analytical sensitivities. The CPU time to solution is depicted in table VII.

TABLE VII.-CPU TIME TO SOLUTION FOR LARGE PROBLEMS WITH THE SQP ALGORITHM

\begin{tabular}{|c|c|c|c|}
\hline 60-bar ring & Forward-swept wing & 20-bay truss & Sensitivity \\
\hline 2.3 & 8.7 & 2.5 & Determinate \\
7.4 & 67.5 & 14.8 & Analytical \\
\hline
\end{tabular}

For the 60-bar trussed ring, the optimum solution was reached in $2.3 \mathrm{CPU}$ sec with approximate sensitivity. The time increased threefold for analytical sensitivity. For the forward-swept wing, the time factor in favor of the approximation was almost eightfold; 8.7 CPU sec with approximation against $67.5 \mathrm{sec}$ for analytical sensitivity. The time ratio was 6 for the 20-bay truss; 2.5 and $14.8 \mathrm{CPU}$ sec with approximate and analytical sensitivities, respectively. Overall, the time to solution increased from threefold to eightfold for the analytical sensitivity. Approximate sensitivity increased computational efficiency by several orders of magnitude.

\section{Convergence Pattern}

The convergence of weight versus CPU time to solution with analytical and approximate sensitivities for the three large problems is depicted in figure 8. For each problem, optimization was begun with the same initial design. Both methods produced similar optimum solutions. Consider the graph in figure 8(a) for the 20-bay truss. The convergence patterns, with and without approximation, portray undulations that are quite similar. However, the convergence is very rapid with the determinate sensitivity. The convergence characteristic is similar for the 60-bar trussed ring and the forward-swept wing shown in figures 8(b) and (c), respectively. 

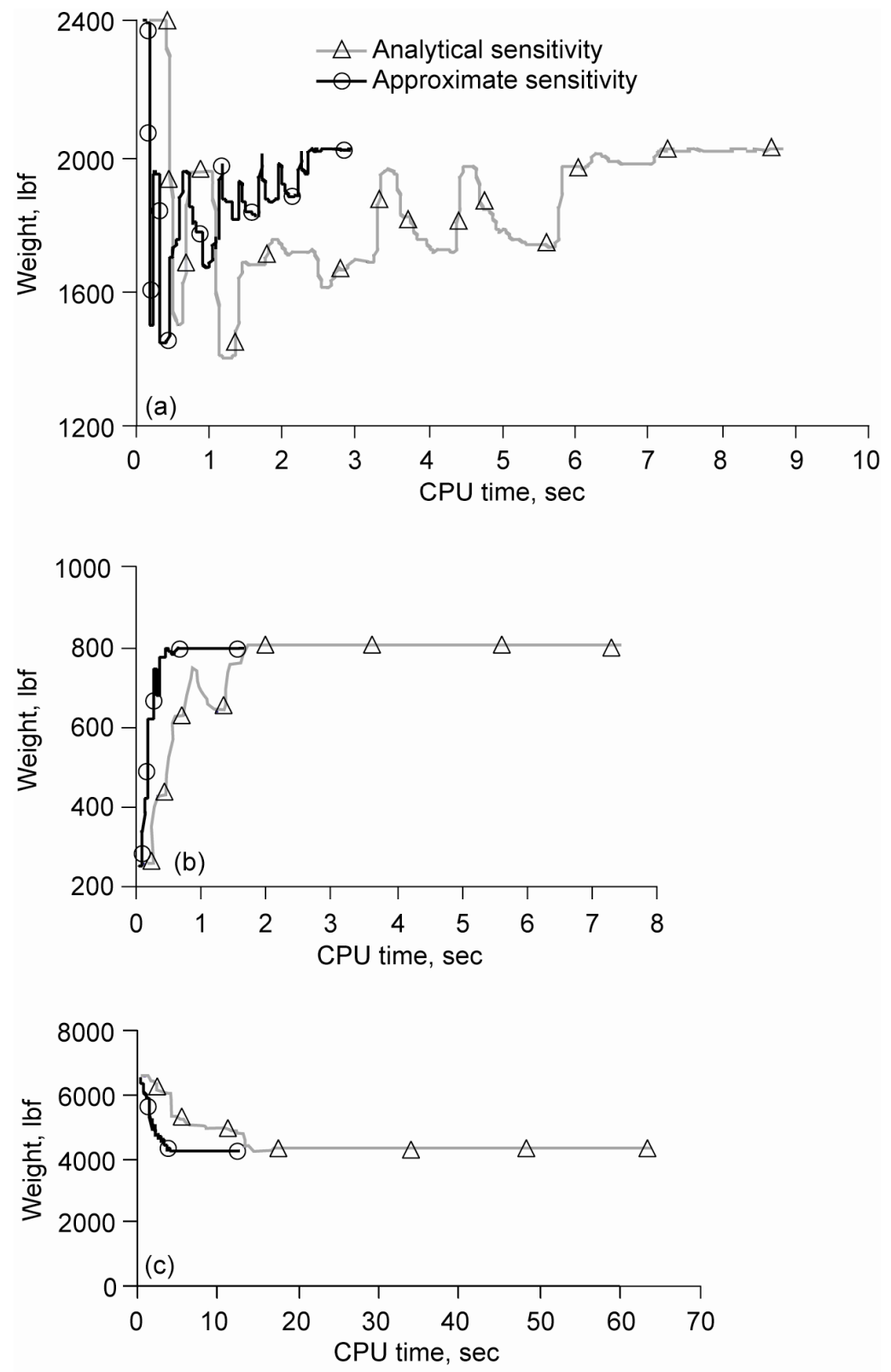

Figure 8.-CPU solution time for SQP algorithm. (a) Twenty-bay truss.

(b) Sixty-bar trussed ring. (c) Forward-swept wing. 


\section{Angle Between Search Directions}

The iterative optimization process moved along a search direction $(\vec{d})$ from one design point to another. The search directions, generated from the gradients, differed for the analytical $\left(\vec{d}_{\text {anl }}\right)$ and determinate sensitivities $\left(\vec{d}_{\text {determinate }}\right)$. If the difference between $\vec{d}_{\text {anl }}$ and $\vec{d}_{\text {determinate }}$ was small, then the contribution to sensitivity from the indeterminate factor could be considered to be negligible. Otherwise, the contribution from the indeterminate factor could be significant. To examine this issue, we defined an angle $\theta_{i}$ at the $i^{\text {th }}$ iteration between search directions generated using determinate $\vec{d}_{\text {determinate }}$ and analytical $\vec{d}_{\text {anl }}$ sensitivities as

$$
\theta_{i}=\cos ^{-1}\left(\frac{\vec{d}_{\text {anl }} \cdot \vec{d}_{\text {determinate }}}{\left|\vec{d}_{\text {anl }}\right|\left|\vec{d}_{\text {determinate }}\right|}\right)_{i}
$$

The angle would be zero $\left(\theta_{i}=0\right)$ if the determinate and the analytical gradients were identical; otherwise, it would be nonzero $\left(\theta_{i} \neq 0\right)$. In some scale, the angle $\theta_{i}$ was a measure of the difference between the closed-form and determinate gradients of the active constraints. For the five-bar truss shown in figure 3, the angle $\theta_{i}$ was calculated at the initial and the optimum design points for the SQP algorithm. Numerical values for the directions and angle are given in table VIII.

TABLE VIII.-ANGLE BETWEEN SEARCH DIRECTIONS SOLVED WITH SQP ALGORITHM FOR THE FIVE-BAR TRUSS

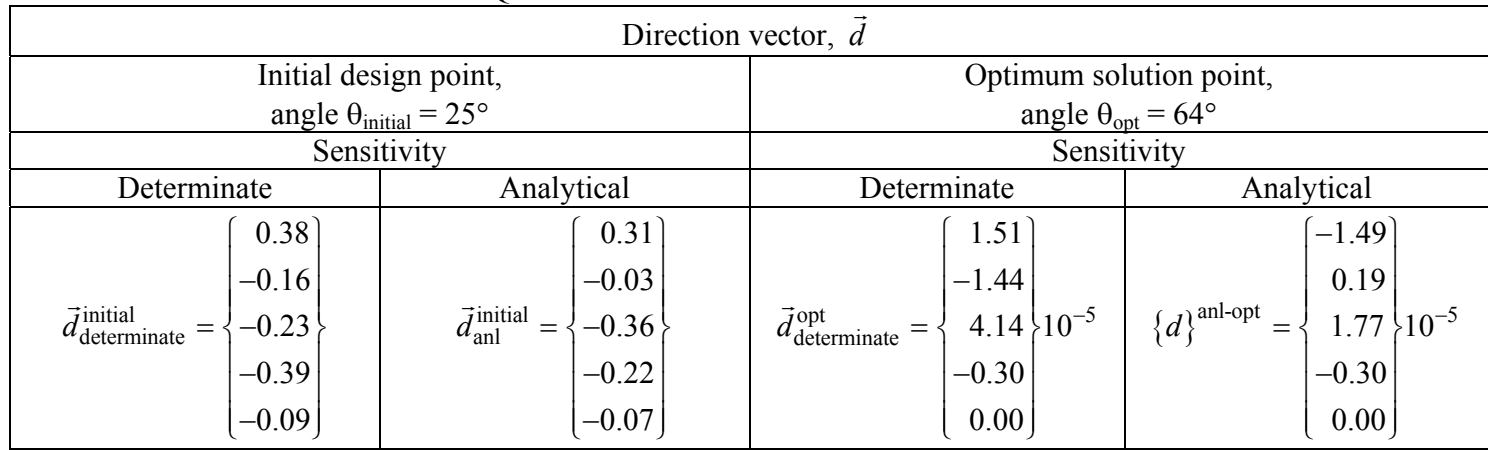

The angle was different at the initial as well as at the optimal design points with values $\theta_{\text {initial }}=25^{\circ}$ and $\theta_{\text {opt }}=64^{\circ}$. For the three large problems, the angles were calculated for the SQP algorithm and are given in table IX. At the initial point, the angles varied from $20^{\circ}$ for the forward-swept wing to $51^{\circ}$ for the 20 -bay truss. At the optimum solution point, the minimum and maximum values for angles were $39^{\circ}$ and $89^{\circ}$, respectively. In summary, the directions taken from the initial point to reach the optimum solu-tion were different for the analytical and the determinate sensitivities. In other words, the indeterminate component of the sensitivities in equation (4) was not negligible and it changed the path of optimization.

TABLE IX.-ANGLE BETWEEN SEARCH DIRECTIONS FOR LARGE PROBLEMS SOLVED WITH SQP ALGORITHM

\begin{tabular}{|l|c|c|}
\hline \multirow{2}{*}{ Problem } & \multicolumn{2}{|c|}{ Angle, $\theta$, deg } \\
\cline { 2 - 3 } & $\begin{array}{c}\text { Initial design point, } \\
\theta_{\text {initial }}\end{array}$ & $\begin{array}{c}\text { Optimum } \\
\text { solution point, } \\
\theta_{\text {opt }}\end{array}$ \\
\hline 60-bar trussed ring & 47 & 39 \\
Forward-swept wing & 20 & 89 \\
20-bay truss & 51 & 40 \\
\hline
\end{tabular}




\section{Discussion}

Design optimization was not sensitive to the precision of the gradients of the stress and displacement constraints of an indeterminate truss. Simple determinate sensitivities performed very well for all design problems. The CPU time to optimum solution was substantially reduced with the determinate sensitivity. The question is: Why did the determinate sensitivity outperform the full closed-form gradient? An answer is attempted through a discussion of the nature of the structural design problem.

\section{Nature of the Structural Design Problem}

The nature of the design optimization problem was examined by considering the three-bar truss shown in figure 2 . The problem had three design variables $\left(A_{1}, A_{2}, A_{3}\right)$. It had three stresses $\left(\sigma_{1}, \sigma_{2}, \sigma_{3}\right)$ and three stress constraints $\left(g_{\sigma 1}, g_{\sigma 2}, g_{\sigma 3}\right)$. Likewise, there were two displacements $\left(X_{1}, X_{2}\right)$ and two constraints $\left(g_{x 1}, g_{x 2}\right)$ for each load case. There were three implicit structural analysis relationships between the five behavior variables:

$$
\begin{gathered}
\sigma_{1}-\sigma_{2}+\sigma_{3}=0 \\
X_{1}=\frac{\ell}{E}\left(\sigma_{2}-2 \sigma_{1}\right) \\
X_{2}=\frac{\ell}{E}\left(\sigma_{2}\right)
\end{gathered}
$$

Equation (11a) is the compatibility condition (CC), and it is expressed in stresses. Equations (11b) and (11c) are the deformation displacement relations, also expressed in stress variables. It is important to observe that the three implicit relationships do not explicitly contain the design variable. In other words, the gradient of one stress can be expressed in terms of the gradient of other stresses. Such as for example, $\left(\nabla \sigma_{2}=\nabla\left(\sigma_{1}+\sigma_{3}\right)\right)$ and $\left(\nabla X_{1}=\frac{\ell}{E}\left(\nabla \sigma_{2}-2 \nabla \sigma_{1}\right)\right)$. If the second stress $g_{\sigma 2}$ and second displacement $g_{x 2}$ constraint become active, then the coefficient matrix $[Q]$ of the direction vector $\{d\}$ in equation (1) will become singular and $\left[\nabla g_{\sigma 2} ; \nabla g_{x 2}\right]$ will become rank deficit. Four possible singularity situations are listed in table X. In case 1 , a member stress $\left(\sigma_{2}\right)$ is dependent on a single displacement $\left(x_{2}\right)$. The rank of the sensitivity matrix was 1 , but it was restored to 2 with the approximation. Consider case 3 with three active constraints. The approximation had a full rank of 3 , whereas the analytical sensitivity had a rank

\begin{tabular}{|c|c|c|c|c|c|}
\hline \multirow[t]{2}{*}{ Case } & \multicolumn{3}{|c|}{ Set of active constraints } & \multicolumn{2}{|c|}{ Rank of sensitivity matrix } \\
\hline & Total & Number of each & Constraints & Analytical & Determinate \\
\hline 1 & 2 & $\begin{array}{l}1 \text { stress and } \\
1 \text { displacement }\end{array}$ & $g_{\sigma 2}, g_{x 2}$ & 1 & 2 \\
\hline 2 & 3 & 3 stresses & $g_{\sigma 1}, g_{\sigma 2}, g_{\sigma 3}$ & 2 & 3 \\
\hline 3 & 3 & $\begin{array}{l}2 \text { stresses and } \\
1 \text { displacement }\end{array}$ & $g_{\sigma 1}, g_{\sigma 2}, g_{x 1}$ & 2 & 3 \\
\hline 4 & 5 & $\begin{array}{c}3 \text { stresses and } \\
2 \text { displacements }\end{array}$ & $g_{\sigma 1}, g_{\sigma 2}, g_{\sigma 3}, g_{x 2}, g_{x 3}$ & 2 & 3 \\
\hline
\end{tabular}
deficit at 2. The other two cases also exhibited deficient rank.

TABLE X.-RANK OF SENSITIVITY MATRIX FOR A THREE-BAR TRUSS 
The four singularity cases listed in table $\mathrm{X}$ cannot be ascertained prior to the initiation of the optimization calculations because constraint activity depends on the value of design variables. Singularity will be avoided when determinate sensitivity is used because it restores the full rank of the sensitivity matrix as shown in table X. In other words, the implicit relationship of the behavior constraints induced singularity in the design optimization of this truss.

\section{Coefficients in Equilibrium and Compatibility Matrices}

The number of stress and displacement components in the implicit relationship, similar to that in equation (11), depends on two quantities: $q_{e e}$ and $q_{c c}$. The number of entries (or nonzero coefficients) in a column of the equilibrium matrix $[B]$ is $q_{e e}$. Likewise, the number of nonzero coefficients in a row of the compatibility matrix [C] is $q_{c c}$. Both $q_{e e}$ and $q_{c c}$ are small numbers. In other words, a small number of stresses are dependent. Likewise, a displacement is dependent on few stresses. Consider the example of the 20-bay truss shown in figure 7 . The number of coefficients in a column of its equilibrium matrix varies between one and four $\left(1 \leq q_{e e} \leq 4\right.$; four is more prevalent). The coefficients in a row of the compatibility matrix range between 6 and $20\left(6 \leq q_{c c} \leq 20\right.$; the typical number is six $)$. Six typical dependence relationships for the truss are given in table XI.

TABLE XI.-RANK OF SENSITIVITY MATRIX FOR A 20-BAY TRUSS

\begin{tabular}{|c|c|c|c|c|}
\hline Case & \multicolumn{2}{|c|}{ Set of constraints } & \multicolumn{2}{|c|}{ Rank of sensitivity matrix } \\
\hline & Number & Constraints & Determinate & Analytical \\
\hline 1 & 2 & $g_{\sigma 1}, g_{x 2}$ & 1 & 2 \\
2 & 3 & $g_{\sigma 4}, g_{x 5}, g_{x 6}$ & 2 & 3 \\
3 & 5 & $g_{\sigma 68}, g_{x 69}, g_{x 70}, g_{x 71}, g_{x 72}$ & 4 & 5 \\
4 & 6 & $g_{\sigma 1}, g_{\sigma 2}, \ldots, g_{\sigma 6}$ & 5 & 6 \\
5 & 6 & $g_{\sigma 31}, g_{\sigma 32}, \ldots, g_{\sigma 36}$ & 5 & 6 \\
6 & 20 & $g_{\sigma 2}, g_{\sigma 7}, \ldots, g_{\sigma 67}$ & 19 & 20 \\
\hline
\end{tabular}

For case 1, one stress and one displacement are dependent because $q_{e e}=1$. For case 2, one stress is dependent on two displacements because $q_{e e}=2$. For case 3, one stress is dependent on four displacements because $q_{e e}=4$. For cases 4 and 5, six stresses are dependent because $q_{c c}=6$. For case 6 , 20 stresses are dependent because $q_{c c}=20$. The sixth case is interesting because the 20 stresses belong to the bottom chord members of the truss. The bottom chord is a natural load path but it can promote singularity in the optimization process, which however, can be avoided when approximate sensitivity is used. For a truss, a small number (in the range of two to six) of active stress and displacement constraints can be dependent.

A traditional structural optimization problem contains dependent constraints. A small number of active stress and displacement constraints can be dependent. The multitude of implicit constraints reduces the rank of the coefficient matrix $[Q]$. Simple determinate sensitivity worked well because it restored the full rank for each of the six cases shown in table XI. Earlier, we suggested (ref. 9) that a set of independent constraints should be separated out of the given stress and displacement constraints by using a singular value decomposition algorithm. The exercise has to be performed before the generation of each search direction. This technique works well for small problems. For larger problems, the decom-position process increases the numerical burden in optimization, which is already computationally intensive. The current recommendation is to use simple determinate sensitivity because it restores the full rank of the matrix $[Q]$ and converges more rapidly. 


\section{Adjustment for the Stiffness Method}

Design is stress driven both for stress and displacement limitations. The area of a truss bar for stress limitation can be updated as $A^{\text {new }}=\frac{\sigma}{\sigma_{0}} A^{\text {old }}$. Likewise, the displacement formula $(X=J G F)$ can be manipulated to obtain an area update formula for the stiffness limitation (ref. 13). The two features make the method of force an attractive tool for design applications. We, however, realize that the stiffness method is very popular. The question is, "Can sensitivities be approximated when the stiffness method is used as the analysis tool in optimization?" Such an approximation is straightforward for the stress constraints. It may pose a challenge for the displacement limitation because it is a global variable. In the stiffness method, the stress sensitivity can be obtained by dividing the force or stress parameters $(F$ or $\sigma)$ by the square of area or area, respectively, $-F / A^{2}$ or $-\sigma / A$. The force or stress output of a stiffness code can be adjusted to obtain the approximate sensitivity for the stress constraints.

The difficulty encountered in calculating the approximate displacement sensitivity is illustrated by considering the three-bar truss as an example. Consider one term in the derivative of the first displacement $X_{1}$ with respect to the area $A_{1}$. For simplicity, one load component is set to zero, $P_{y}=0$. The closed-form derivative can be written as

$$
\frac{\partial X_{1}}{\partial A_{1}}=-\frac{2\left(\sqrt{2} A_{3}^{2}+4 A_{2} A_{3}+2 \sqrt{2} A_{2}^{2}\right) \ell P_{x}}{E\left(\sqrt{2} A_{2} A_{3}+2 A_{1} A_{3}+\sqrt{2} A_{1} A_{2}\right)^{2}}
$$

The procedure of separating the sensitivity into determinate and indeterminate factors in equation (8) cannot be directly extended to the stiffness method, such as for example in equation (12). The stiffness method, in general, appears to have two major impediments for design calculations.

(1) The method has fewer equations $m$ than the number of design variables $n: m \leq n$. The three-bar truss has three design variables, three bar stresses, but there are only two stiffness equations. Three

equations are required to size the three bar areas, like $A_{1}=\left|\frac{F_{1}}{\sigma_{0}}\right|, A_{2}=\left|\frac{F_{2}}{\sigma_{0}}\right|$, and $A_{3}=\left|\frac{F_{3}}{\sigma_{0}}\right|$. In other words, it is not easy to link bar areas to displacements. At best, this link would provide a relationship of three design variables to two displacements, and it would not be a one-to-one mapping.

(2) The stiffness method does not allow free movement between analysis variables like IFM, which allows movement from force to displacement, $\{X\}=[J][G]\{F\}$, and vice versa, $\{F\}=[G]^{-1}[B]^{T}\{X\}$. The two formulas, along with their governing equation, $[S]\{F\}=\{P\}$, make IFM a very attractive tool for sensitivity calculation and design optimization.

In the stiffness method, the sensitivity expression given by equation (9) can be used provided the matrix $[J]$ can be approximated. For static response only, it can be approximated as $[\mathrm{J}]=\left[\frac{\left[B B^{T}\right]^{-1}}{[0]}\right]^{T}$. The generation of the equilibrium matrix is straightforward because this, in essence, is the concatenation of the transformation submatrices used to change the local to the global coordinate systems. The inverse of $\left[B B^{T}\right]$ cannot be avoided, except that $[B]$ is a very sparse matrix.

\section{Extension to Other Structure Types}

Extension of the approximate expressions is straightforward for beams and framework. Consider, for example, a beam with moment as the analysis variable and moment of inertia $I$ and depth $d$ as the design 
variables. The flexure formula can be differentiated to obtain the approximate sensitivity for stress constraints:

$$
\sigma=\frac{M\left(\frac{d}{2}\right)}{I} \Rightarrow \frac{\partial \sigma}{\partial I}=-\frac{M d}{2 I^{2}}+\left[\text { neglect } \rightarrow\left(\frac{d}{2 I} \frac{\partial M}{\partial I}\right)\right]
$$

The derivative of the moment in the displacement formula $(X=J G F)$ would provide the approximate sensitivity of the stiffness constraints. In other words, in IFM, the generation of the closed-form and approximate expressions for beams is quite straightforward. The logic can be extended for framework that would require a mixing of the truss and beam expressions. Then computer software has to be developed to compare design optimizations using approximate and analytical sensitivities for such structures. The exercise is worth the effort because singularity can be eliminated to make optimization robust for flexural structures.

\section{Conclusions}

There are numerous dependent constraints in the design optimization problem of an indeterminate truss. A small set of stresses can be dependent. A stress also can depend on a few displacements. A truss design with many sets of dependent constraints may not be a well-posed mathematical programming optimization problem. However, it is a real-life industrial design problem. In optimization calculations, all constraints should be used in defining the feasible region. Sensitivities of only the independent constraints should be used to calculate the direction vector. The independence criterion will be satisfied when the proposed simple determinate design sensitivity is used. The optimum solution was reached with the determinate sensitivity even though the search directions differed for the determinate and analytical sensitivities. The use of simple determinate sensitivity substantially reduced the CPU time to solution. The integrated force method is an efficient analysis tool for the calculation of determinate sensitivity in particular and for design application in general. The concept of using approximate sensitivity in design optimization should be extended to flexural structures like beams and framework. 


\section{Appendix-Symbols}

$\begin{array}{ll}A_{i} & \text { bar areas } \\ {[B]} & m \times n \text { equilibrium matrix } \\ {[C]} & r \times n \text { compatibility matrix } \\ d & \text { search direction } \\ \vec{d}_{\text {determinate }}, \vec{d}_{\text {anl }} & \text { search directions for determinate and analytical sensitivities } \\ E & \text { Young's modulus } \\ F & \text { member force } \\ {[G]} & n \times n \text { flexibility matrix } \\ g_{i} & i^{\text {th }} \text { constraint } \\ {[\nabla g]} & \text { sensitivity matrix } \\ {[J]} & \text { first } m \text { rows of }\left[[S]^{-1}\right]^{T} \\ m & \text { number of displacements } \\ n & \text { number of internal forces } \\ \{P\} & \text { load vector } \\ q_{c c} & \text { number of entries in a row of the compatibility matrix }[C] \\ q_{e e} & \text { number of entries in a column of the equilibrium matrix }[B] \\ r=n=m & \text { number of dependent members or compatibility conditions } \\ {[S]} & n \times n \text { IFM governing matrix } \\ u_{j} & \text { nodal displacement } \\ u_{j o} & \text { limitation on nodal displacement } \\ W & \text { weight } \\ x, y, z & \text { coordinates } \\ \rho_{i} & \text { weight density for } i^{\text {th }} \text { bar } \\ \sigma_{i} & \\ \sigma_{0} & \text { allowable stress } \\ & \end{array}$





\section{References}

1. Adelman, H.W.; and Haftka, R.T.: Sensitivity Analysis in Engineering. NASA CP-2457, 1987.

2. Choi, K.K.; and Kim, N.H.: Structural Sensitivity Analysis and Optimization, vol. 1. Springer, New York, NY, 2005.

3. Kirsch, U.: Design-Oriented Analysis of Structures: A Unified Approach. Kluwer Academic Publishers, Dordrecht, Netherlands, 2002.

4. Vervenne, K.: Design Sensitivity Analysis. Technical Report, Delft University of Technology, LTM 1234, 2000.

5. Kibsgaad, S.: Sensitivity Analysis - the Basis for Optimization. Int. J. Numer. Meth. Engrg., vol. 34, no. 3, 1992, pp. 901-932.

6. Kolonay, R.M.; Nagendra, S.; and Laflen, J.: Sensitivity of Turbine Blade Components. 7th AIAA/USAF/NASA/ISSMO, Symposium on Multidisciplinary Analysis and Optimization. St. Louis, MO, 1998.

7. MSC/Nastran 2001-Release Guide. MSC.Software Corporation, Los Angeles, CA, 2001.

http://www.mscsoftware.com/support/prod_support/nastran/documentation/release2001.pdf (accessed Aug. 10, 2005).

8. Wujek, B.A.; and Renaud, J.E.: Automatic Differentiation for More Efficient System Analysis and Optimization. Engrg. Opt., vol. 31, no. 1, 1998, pp. 101-139.

9. Patnaik, S.N.; Guptill, J.D.; and Berke, L.: Singularity in Structural Optimization. Int. J. Numer. Meth. Engrg., vol. 36, no. 6, 1993, pp. 931-944.

10. Patnaik, S.N.; and Hopkins, D.A.: Strength of Materials: A Unified Theory for the 21 st Century. Elsevier, Amsterdam, Netherlands, 2004.

11. Patnaik, S.N.; and Gallagher, R.H.: Gradients of Behaviour Constraints and Reanalysis Via the Integrated Force Method. Int. J. Numer. Meth. Engrg., vol. 23, no. 12, 1986, pp. 2205-2212.

12. Guptill, J.D., et al.: CometBoards Users Manual. Release 1.0. NASA TM-4537, 1997.

13. Patnaik, S.N.; Gendy, A.S.; and Hopkins, D.A.: Modified Fully Utilized Method (MFUD) for Stress and Displacement Constraints. Int. J. Numer. Meth. Engrg., vol. 41, 1998, pp. 1171-1194. 


\begin{tabular}{|c|c|c|}
\hline \multicolumn{2}{|c|}{ REPORT DOCUMENTATION PAGE } & $\begin{array}{l}\text { Form Approved } \\
\text { OMB No. 0704-0188 }\end{array}$ \\
\hline \multicolumn{3}{|c|}{$\begin{array}{l}\text { Public reporting burden for this collection of information is estimated to average } 1 \text { hour per response, including the time for reviewing instructions, searching existing data sources } \\
\text { gathering and maintaining the data needed, and completing and reviewing the collection of information. Send comments regarding this burden estimate or any other aspect of thi } \\
\text { collection of information, including suggestions for reducing this burden, to Washington Headquarters Services, Directorate for Information Operations and Reports, } 1215 \text { Jefferson } \\
\text { Davis Highway, Suite 1204, Arlington, VA 22202-4302, and to the Office of Management and Budget, Paperwork Reduction Project (0704-0188), Washington, DC 20503. }\end{array}$} \\
\hline 1. AGENCY USE ONLY (Leave blank) & \begin{tabular}{|c|c|} 
2. REPORT DATE & 3. \\
May 2006 &
\end{tabular} & $\begin{array}{l}\text { ID DATES COVERED } \\
\text { Technical Paper }\end{array}$ \\
\hline \multicolumn{2}{|c|}{ Precision of Sensitivity in the Design Optimization of Indeterminate Structures } & 5. FUNDING NUMBERS \\
\hline \multicolumn{2}{|c|}{$\begin{array}{l}\text { 6. AUTHOR(S) } \\
\text { Surya N. Patnaik, Shantaram S. Pai, and Dale A. Hopkins }\end{array}$} & WBS-22-708-24-05 \\
\hline $\begin{array}{l}\text { 9. SPONSORING/MONITORING AGEI } \\
\text { National Aeronautics and Sp } \\
\text { Washington, DC 20546-00 }\end{array}$ & $\begin{array}{l}\text { NAME(S) AND ADDRESS(ES) } \\
\text { Administration }\end{array}$ & $\begin{array}{l}\text { 10. SPONSORING/MONITORING } \\
\text { AGENCY REPORT NUMBER } \\
\text { NASA TP-2006-213818 }\end{array}$ \\
\hline
\end{tabular}

11. SUPPLEMENTARY NOTES

Surya N. Patnaik, Ohio Aerospace Institute, 22800 Cedar Point Road, Brook Park, Ohio 44142; Shantaram S. Pai and Dale A. Hopkins, NASA Glenn Research Center. Responsible person, Surya N. Patnaik, organization code RXS, 216-433-5916.

12a. DISTRIBUTION/AVAILABILITY STATEMENT 12b. DISTRIBUTION CODE

Unclassified - Unlimited

Subject Category: 39

Available electronically at http://gltrs.grc.nasa.gov

This publication is available from the NASA Center for AeroSpace Information, 301-621-0390.

13. ABSTRACT (Maximum 200 words)

Design sensitivity is central to most optimization methods. The analytical sensitivity expression for an indeterminate structural design optimization problem can be factored into a simple determinate term and a complicated indeterminate component. Sensitivity can be approximated by retaining only the determinate term and setting the indeterminate factor to zero. The optimum solution is reached with the approximate sensitivity. The central processing unit (CPU) time to solution is substantially reduced. The benefit that accrues from using the approximate sensitivity is quantified by solving a set of problems in a controlled environment. Each problem is solved twice: first using the closed-form sensitivity expression, then using the approximation. The problem solutions use the CometBoards testbed as the optimization tool with the integrated force method as the analyzer. The modification that may be required, to use the stiffener method as the analysis tool in optimization, is discussed. The design optimization problem of an indeterminate structure contains many dependent constraints because of the implicit relationship between stresses, as well as the relationship between the stresses and displacements. The design optimization process can become problematic because the implicit relationship reduces the rank of the sensitivity matrix. The proposed approximation restores the full rank and enhances the robustness of the design optimization method.

\begin{tabular}{|c|c|c|c|}
\hline \multirow{3}{*}{\multicolumn{3}{|c|}{$\begin{array}{l}\text { 14. SUBJECT TERMS } \\
\text { Approximate sensitivity; Design; Optimization; Singularity; Implicit relationship; } \\
\text { Indeterminate structure }\end{array}$}} & \multirow{3}{*}{$\begin{array}{l}\text { 15. NUMBER OF PAGES } \\
28 \\
\text { 16. PRICE CODE }\end{array}$} \\
\hline & & & \\
\hline & & & \\
\hline $\begin{array}{l}\text { 17. SECURITY CLASSIFICATION } \\
\text { OF REPORT }\end{array}$ & $\begin{array}{l}\text { 18. SECURITY CLASSIFICATION } \\
\text { OF THIS PAGE }\end{array}$ & $\begin{array}{l}\text { 19. SECURITY CLASSIFICATION } \\
\text { OF ABSTRACT }\end{array}$ & 20. LIMITATION OF ABSTRACT \\
\hline Unclassified & Unclassified & Unclassified & \\
\hline
\end{tabular}



